Review Article

\title{
Antiviral Phytocompounds: A Methodical Review of Therapeutic Efficiency Against SARS-Like Human Coronaviruses
}

\author{
Yahyea Baktiar Laskar¹, Udaya Kumar Vandana², Sayani Roy², Pranab Behari Mazumder ${ }^{*}$, \\ Anupam Das Talukdar ${ }^{3}$, Ajaikumar B. Kunnumakkara ${ }^{4}$ and Monjur Ahmed Laskar

${ }^{1}$ Natural product and Biomedicine Research Laboratory, Department of Biotechnology, Assam University, Silchar, India ${ }^{2}$ Microbial Molecular Biology Laboratory, Department of Biotechnology, Assam University, Silchar, India

${ }^{3}$ Ethnobotany and Medicinal Plant Research Laboratory, Department of Life Science \& Bioinformatics, Assam University, Silchar, India

${ }^{4}$ Cancer Biology Laboratory, Department of Biosciences and Bioengineering, Indian Institute of Technology, Guwahati, India

${ }^{5}$ Bioinformatics Centre, Department of Life Science \& Bioinformatics, Assam University, Silchar, India

\begin{abstract}
Introduction: Coronaviruses are a group of rapidly evolving and single-stranded RNA viruses that cause mild upper respiratory infections. The casualty caused by coronavirus diseases like the Severe Acute Respiratory Syndrome (SARS) in 2004, Middle East respiratory syndrome (MERS) in 2012 and the recently discovered SARS-like disease, Coronavirus disease 2019 (CoVID-19) has been recognized as a threat to public health. Considering all coronaviruses shares similarity in genomic architecture and clinical manifestations, this study is aimed to summarize present knowledge about the therapeutic efficiency of medicinal plant and their compounds against SARS-like human coronaviruses and to report potential preventive drug templates from natural products.
\end{abstract}

Methods: In this comprehensive review, we have assembled and investigated available published information on natural products with potent anti-viral activity against the pathogenesis of SARS-like coronaviruses from different electronic databases. Systematically we have included plants and their compounds that have been historically active against RNA viruses including SARS-like coronaviruses.

Results: This study observed that promising therapeutic outcome can be anticipated from at least fifteen such traditionally used phytocompounds in the prevention and treatment of coronavirus diseases and its associated health complexities.

Discussion/Conclusions: Because of a variable genome in RNA viruses, it is very difficult to design a drug or vaccine that is effective in the long term. Parallel to contemporary medicines, plant-based natural products with antiviral potential can also be assessed for their efficiency and safety against these diseases.

Keywords

SARS-CoV-2, SARS, MERS, Coronavirus Disease, Phytomedicine, Phytochemical

\section{Introduction}

Coronaviruses are a group of rapidly evolving, single-stranded (+) RNA viruses that cause mild to moderate upper respiratory infections generally spread through airborne droplets to the nasal mucosa [1,2]. Previously the two subgroups of coronaviruses and their serotypes - the alpha-coronaviruses (229E, NL63) and the beta-coronaviruses (OC43, HKU1) were known to cause mild respiratory illnesses in human $[1,3]$. In 2003-2005, a newly discovered beta-coronavirus in China caused SARS with an estimated 8,098 reported cases [4]. Again in 2012, the Middle East respiratory syndrome (MERS) caused by another SARS-like coronavirus belonging to the order Nidovirales took 858 lives as reported by the World
Health Organization (WHO) [5]. Recently the emergence of a highly infectious beta-coronavirus, the SARS coronavirus 2 or

*Corresponding author: Prof. Dr. Pranab Behari Mazumder, Professor \& Head, Department of Biotechnology, Assam University, Silchar-788011, Assam, India, Tel: +91-9435075765

Accepted: November 10, 2020

Published online: November 12, 2020

Citation: Laskar YB, Vandana UK, Roy S, et al. (2020) Antiviral Phytocompounds: A Methodical Review of Therapeutic Efficiency Against SARS-Like Human Coronaviruses. J Plant Biotechnol Res 1(1):26-34 
Citation: Laskar YB, Vandana UK, Roy S, et al. (2020) Antiviral Phytocompounds: A Methodical Review of Therapeutic Efficiency Against SARSLike Human Coronaviruses. J Plant Biotechnol Res 1(1):26-34

SARS-CoV-2 that causes coronavirus disease 2019 (CoVID-19) which lead to a global public health emergency $[6,7]$. The first appearance of the disease in China and its subsequent global spread affected more than 12.7 million people worldwide while causing 0.56 million deaths as of July 2020 with a $2 \%$ crude case fatality rate [8].

All these viruses mostly originate in mammals other than human and rapidly evolve to become contagious to human [3]. Phylogenetically, all coronaviruses show a typical genomic homology with 14 open reading frames (ORFs) that encode 27 proteins [9]. Typically, the ORF1 and ORF2 encode 15 non-structural proteins (Nsps) essential for replication and other structural proteins like spike protein (S), envelope protein (E), membrane protein (M), nucleocapsid (N) and other accessory proteins [10]. Among them, blocking the envelope projects glycoproteins known as Spike-glycoprotein or S-protein is considered as a vital step in preventing the pathogenesis of coronaviruses as it is crucial for host cell attachment and entry [10]. Further, the established biological function and presence of vital enzyme active site in Nsps like chymotrypsin-like main protease $\left(3 \mathrm{CL}^{\text {pro }}\right)$, Papain-like proteinase ( $\left.\mathrm{PL}^{\text {pro }}\right)$, RNA-dependent RNA polymerase $(R d R p)$ and helicase are considered as excellent therapeutic targets for developing small-molecule inhibitors $[11,12]$. Especially, the highly conserved $3 \mathrm{CL}^{\text {pro }}$ is considered a key therapeutic target for its multifunctional role in the production of functional proteins that are essential for viral replication [13]. The $3 \mathrm{CL}^{\text {pro }}$ along with $\mathrm{PL}^{\text {pro }}$ processes replicase polyprotein involved in the transcription and replication of viral RNAs [13-15]. The RdRp or nsp12 is the most versatile enzymes of coronaviruses that play a central role in the replication and transcription machinery that leads to the synthesis of viral RNAs $[16,17]$. Apart from these, double-stranded RNA unwinding helicase or nsp13 is also suggested as a possible target to tackle coronaviruses $[18,19]$. Besides, nsp1, nsp3c, and ORF7a are the major virulence factors of coronaviruses that impede the host's innate immunity and help the virus escaping the immune response, and hence they are considered as therapeutic targets [12]. Thus, non-covalent inhibitors of these viral proteins could serve as templates for developing therapeutic antivirals $[20,21]$. As several investigations are underway to design an effective vaccine or drug that can break the viral infection with adequate safety measures, thus far no specific vaccines or drugs are available to treat coronavirus infections. Reportedly encouraging results with rapid symptom improvement was specifically observed with the early combinatory clinical trial of lopinavir-ritonavir HIV antivirals, favipiravir, remdesivir in CoVID-19 patients [22-24]. Besides, antimalarial chloroquine and hydroxychloroquine gained intense attention for their efficiency against SARS-like coronaviruses $[25,26]$. Although conventional antivirals and some other drugs are showing promising outcomes, their efficiency and safety in patients of coronaviral diseases are still ambiguous [27].

Consequently, researchers are considering some alternative approaches like herbal therapies using antiviral medicinal plants or their bioactive components to design specific herbal cure of coronavirus diseases [28]. Considering the role of antiviral medicinal plants in both traditional and modern therapies, their bioactive constituents may help to design an efficient and cost-effective preventive cure against the pathogenesis of rapidly evolving RNA viruses including coronaviruses (CoV) [29]. Historically, several antiviral medicinal plants and their bioactive constituents are used against viral diseases like Influenza, acquired immunodeficiency syndrome (AIDS), hepatitis, and CoV-diseases particularly MERS and SARS [29-32]. Given the identical genomic organization and similar clinical manifestation of all coronaviruses, we have amassed all available information on antiviral plants and their bioactive compounds that were reported previously to exhibit strong inhibitory activity especially against major proteases of SARS-coronaviruses. Previously published information on such plants and their phytocompounds were retrieved from different electronic databases like Elsevier, PubMed, and Google Scholar intending to summarize current knowledge and to report their feasibility in the treatment of coronaviral diseases. This comprehensive data analysis revealed that at least fifteen such phytocompounds could play a significant role in the long-term prevention and treatment of coronaviral pathogenesis that must be validated in a proper clinical setup.

\section{Materials and Methodology}

This methodological review was carried out in June 2020 through a literature survey of all the related published articles in the last 20 years. For this, available information was retrieved from specialized electronic databases like Elsevier, PubMed, and Google Scholar using a combination of several keywords: coronavirus, human coronavirus, SARS, MERS, natural product, plant extract, plant product, phytochemicals, herbal product, and antiviral. The inclusion criteria for selecting article were based on the type of study, type of plant extract (pure/crude), isolated bioactive natural compound, the historical effectiveness against RNA viruses, specific effects against human coronaviruses, clinical and preclinical studies, and articles showing keywords in the title, abstract or full text. Articles reporting in-silico predictions and other systematic reviews were excluded from the study. The repeated articles were removed and the remaining portion was revised to manually reject the articles that did not satisfy the selection criteria. For pure compounds, data related to their therapeutic target, inhibitory concentrations and plant source were noted. For crude extracts, data related to the part of the plant, type of extract, inhibitory concentrations and mode of bioactivity were recorded.

\section{Results and Discussion}

\section{Selection of articles}

Preliminary the article retrieval process identified 341 articles in the databases Elsevier, PubMed, and Google Scholar. Among them, 40 articles satisfied the inclusion criteria and necessary data was extracted from them. The general characteristics of the clinical and pharmacological aspects of the plant extracts and their phytocompounds identified by this review are listed in Table 1 and Table 2 . The chemical structure of some potential antiviral phytocompounds identified by this study is shown in Figure 1. 
Citation: Laskar YB, Vandana UK, Roy S, et al. (2020) Antiviral Phytocompounds: A Methodical Review of Therapeutic Efficiency Against SARSLike Human Coronaviruses. J Plant Biotechnol Res 1(1):26-34

\section{Anti-SARS-CoV phytocompounds}

Since, SARS-like human coronaviruses resemble high similarity in several aspects like genomic organization, receptor binding, and drug targets, thus previously reported phytocompounds and/or their derivatives that showed potent antiviral activity could be used as a template to design anti-SARS-coronavirus therapeutic $[10,33]$. Below we've listed fifteen such phytocompounds that are historically known to have astonishing antiviral activities against the pathogenesis of RNA viruses and were proven to be bioactive against SARSCoV-induced cytopathogenicity in cell-based studies.

Aescin: Aescin is a natural mixture of triterpene saponin isolated from Aesculus hippocastanum was found to inhibit viral replication of SARS-CoV (H.K. strain) infected Vero E6 cells at an inhibitory concentration $\left(\mathrm{EC}_{50}\right)$ of $6.0 \mu \mathrm{M}$ [34].
Aescin has clinical significance as a potent anti-inflammatory agent, however, its antiviral mechanism is unknown [34,35]. The anti-inflammatory activity of aescin is primarily attributed to the hypoxia-activated reduced adhesiveness of neutrophils and the associated release of inflammatory mediators [35]. The $\beta$-escin, a structural form of Aescin isolated from the same plant exhibited selective virucidal activity $\left(\mathrm{EC}_{50}=1.5-\right.$ $2.4 \mathrm{\mu g} / \mathrm{ml}$ ) and hindered replication of Herpes Simplex Virus type-1(HSV-1), Vesicular Stomatitis Virus, Adenovirus 5 and Dengue Virus type 2 propagated in human corneal cells and human conjunctival cells $[35,36]$.

Amentoflavone: Amentoflavone is a common biflavonoid compound found in more than 120 plant species [37]. Amentoflavone isolated especially from Torreya nucifera is known for its potent antiviral activity against several viral diseases

Table 1: Plant extracts that exhibited bioactivity against the cytopathogenicity of previously discovered human and murine coronaviruses

\begin{tabular}{|c|c|c|c|c|c|}
\hline Plant name & Part used & Extract type & Viral disease & Mechanism of action & $\mathrm{EC}_{50} / \mathrm{IC}_{50}(\mu \mathrm{g} / \mathrm{ml})$ \\
\hline Artemisia annua & Whole plant & Ethanol & SARS [66] & $\downarrow C P E$ & $34.5-39.2$ \\
\hline Pyrrosia lingua & Leaf & Chloroform & SARS [66] & $\downarrow C P E$ & $40.5-43.2$ \\
\hline Lindera aggregate & Root & Ethanol & SARS [66] & $\downarrow \mathrm{CPE}$ & $80.6-88.2$ \\
\hline Houttuynia cordata & Whole plant & Water & SARS [95] & $\begin{array}{l}\mathrm{CD4}^{+} \uparrow, \mathrm{CD}^{+} \uparrow \mathrm{IL}-2 \uparrow, \mathrm{IL}- \\
10 \uparrow,-3 \mathrm{CL}^{\text {pro }}\end{array}$ & 1000 \\
\hline Rheum palmatum $L$. & -- & Ethanol & SARS [96] & $\dashv 3 C L^{\text {pro }}$ & $13.76 \pm 0.03$ \\
\hline Isatis indigotica & Root & Water & SARS [90] & $\dashv 3 C L^{\text {pro }}$ & $217-1210 \mu \mathrm{M}$ \\
\hline Euphorbia Neriifolia & Leaf & Ethanol & HCoV [100] & Decreased survival & -- \\
\hline Toona sinensis & Leaf & Water & SARS [101] & $\downarrow C P E$, Inhibit replication & -- \\
\hline Cibotium barometz & -- & Methanol & SARS [97] & $\downarrow C P E,-3 \mathrm{CL}^{\text {pro }}$ & $39 \pm 3$ \\
\hline Gentiana scabra & -- & Water & SARS [97] & $\downarrow C P E,-3 C L^{\text {pro }}$ & $>50$ \\
\hline Dioscorea batatas & -- & Methanol & SARS [97] & $\downarrow C P E,-3 \mathrm{CL}^{\text {pro }}$ & $44 \pm 2$ \\
\hline Cassia tora & -- & Water & SARS [97] & $\downarrow C P E,-3 C L^{\text {pro }}$ & $>50$ \\
\hline Taxillus chinensis & - & Water & SARS [97] & $\downarrow C P E,-3 C^{\text {pro }}$ & $>50$ \\
\hline Cinnamomi cortex & -- & Butanol & SARS [91] & $\downarrow \mathrm{CPE}$ & $7.8 \pm 0.3$ \\
\hline Caryophylli flos & -- & Butanol & SARS [91] & $\downarrow \mathrm{CPE}$ & $51.3 \pm 4.9$ \\
\hline Tribulus terrestris & Fruit & Methanol & SARS [98] & $f P L^{\text {pro }}$ & $15.8-44.4$ \\
\hline Paulownia tomentosa & Fruit & Methanol & SARS [98] & $f P L^{\text {pro }}$ & $5.0-14.4 \mu \mathrm{M}$ \\
\hline
\end{tabular}

$\mathrm{CPE}=$ Cytopathogenic effect; $\mathrm{HCoV}=$ Human Coronaviruses; IL = interleukin; 3CLpro = 3C-like protease; PLpro = Papain-like protease; ' $\uparrow '=$ increased/up-regulated; ' $\downarrow$ ' = decreased/down-regulated; ' $f$ ' = inhibition.

Table 2: A summary of anti-SARS-CoV phytocompounds and their possible therapeutic target and efficiency.

\begin{tabular}{|c|c|c|c|c|c|}
\hline \multicolumn{2}{|c|}{ Therapeutic target } & \multirow{2}{*}{\begin{tabular}{|l|} 
Compound \\
Ginsenoside-Rb1 \\
\end{tabular}} & \multirow{2}{*}{$\begin{array}{l}\mathrm{IC}_{50} / \mathrm{EC}_{50} \\
100 \mu \mathrm{M}\end{array}$} & \multirow{2}{*}{\begin{tabular}{|l|} 
Plant of origin \\
Panax ginseng
\end{tabular}} & \multirow{2}{*}{\begin{tabular}{|l|} 
Ref. \\
{$[34]$}
\end{tabular}} \\
\hline \multirow{7}{*}{ 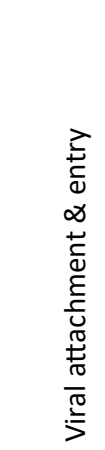 } & \multirow{3}{*}{ S-protein } & & & & \\
\hline & & Glycyrrhizin & $>500 \mu \mathrm{M}$ & $\begin{array}{l}\text { Glycyrrhiza glabra } \\
\text { Glycyrrhiza radix }\end{array}$ & {$[60,62]$} \\
\hline & & Cepharanthine & $6-9.5 \mu \mathrm{g} / \mathrm{ml}$ & Stephania sp. & [48] \\
\hline & \multirow{2}{*}{ ACE2 } & Emodin & $200 \mu \mathrm{M}$ & $\begin{array}{l}\text { Rheum rhabarbarum } \\
\text { Rheum officinale }\end{array}$ & {$[52]$} \\
\hline & & Cepharanthine & $0.98 \mu \mathrm{M}$ & Stephania japonica & [49] \\
\hline & \multirow{2}{*}{ Unclear } & Saikosaponin B2 & $1.7 \mu \mathrm{mol} / \mathrm{L}$ & Bupleurumchinense & [69] \\
\hline & & Lycorine & $15.7 \mu \mathrm{M}$ & Lycoris radiata & {$[66]$} \\
\hline
\end{tabular}


Citation: Laskar YB, Vandana UK, Roy S, et al. (2020) Antiviral Phytocompounds: A Methodical Review of Therapeutic Efficiency Against SARSLike Human Coronaviruses. J Plant Biotechnol Res 1(1):26-34

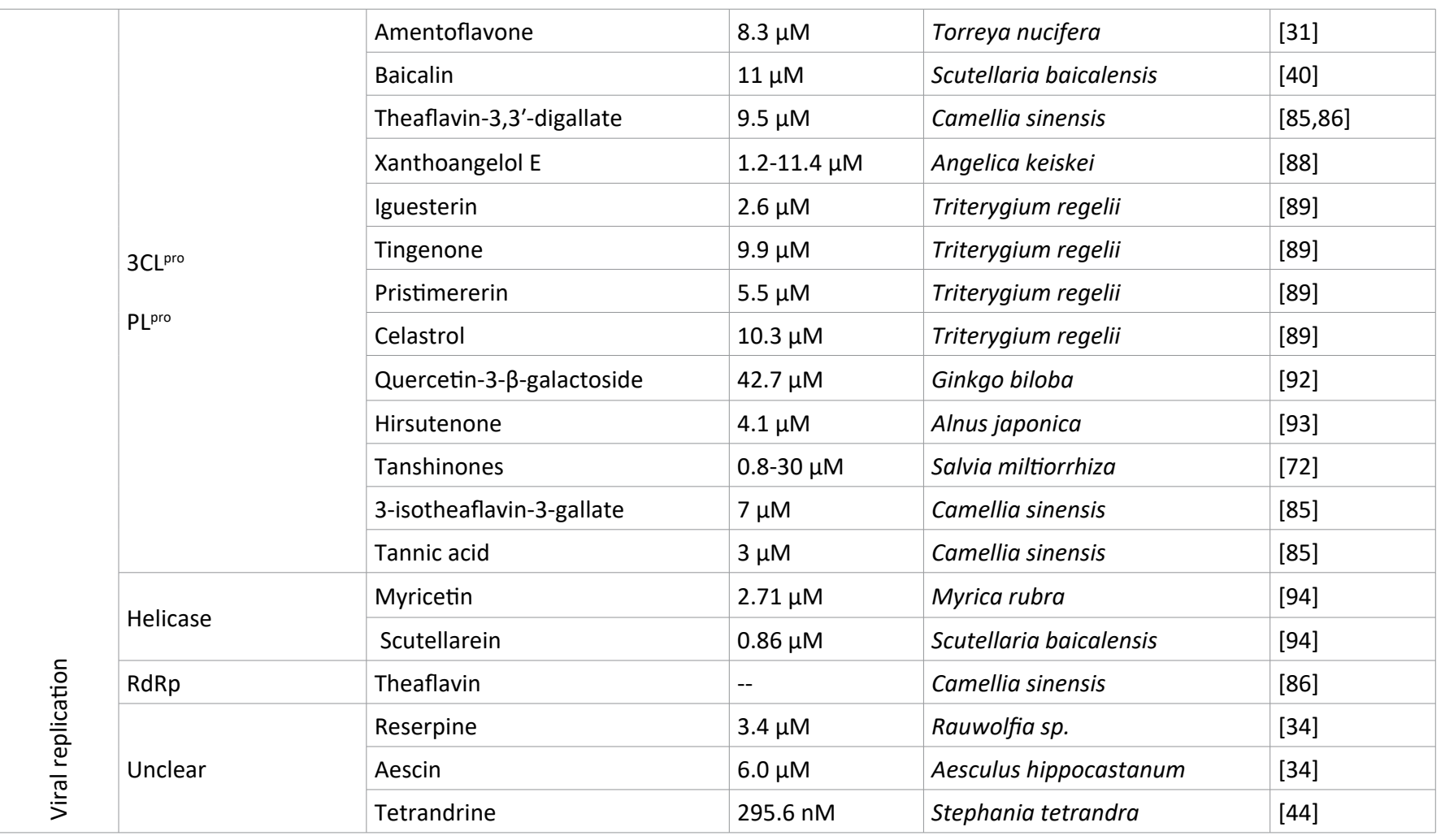

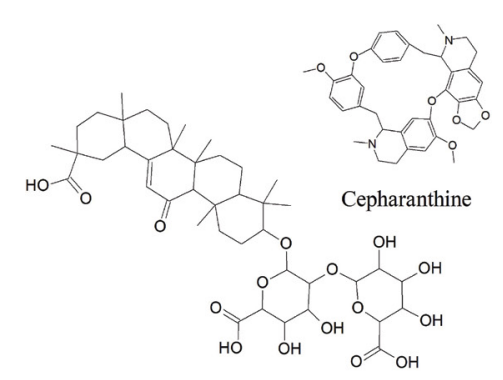

Glycyrrhizin

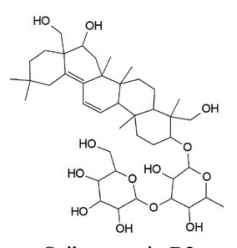

Saikosaponin B2

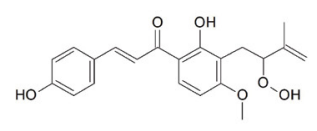

Xanthogelol E<smiles>Cc1coc2c1C(=O)C(=O)c1c-2ccc2c1CCCC2(C)C</smiles>

Tanshinone IIA

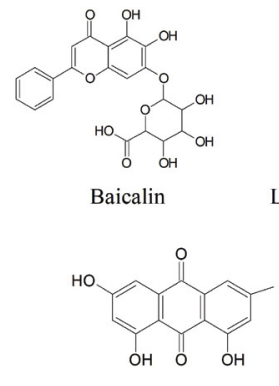

Emodin
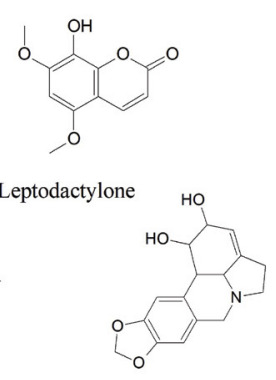

Lycorine

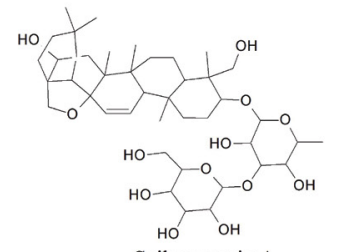

Saikosaponin A

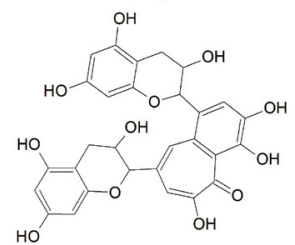

Theaflavin

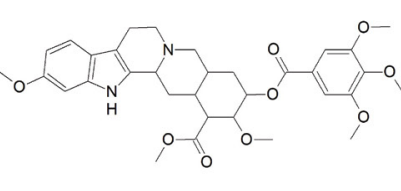

Reserpine

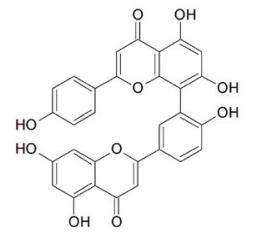

Amentoflavone
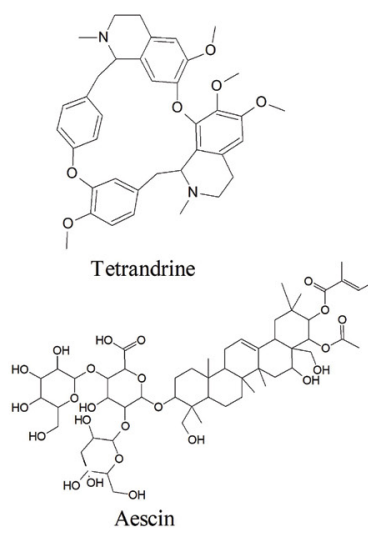

Figure 1: Antiviral Phytocompounds: Some plant-derived compounds that could be a potential therapeutic lead for the prevention and treatment of Human coronaviruses. 
Citation: Laskar YB, Vandana UK, Roy S, et al. (2020) Antiviral Phytocompounds: A Methodical Review of Therapeutic Efficiency Against SARSLike Human Coronaviruses. J Plant Biotechnol Res 1(1):26-34

including dengue, coxsackie virus B3, human immunodeficiency virus (HIV), and respiratory syncytial virus (RSV) [37]. The biflavonoid showed inhibitory activities against chymotrypsin-like protease $\left(3 \mathrm{CL}^{\text {pro }}\right)$ of SARScoronavirus with a low inhibitory concentration of $8.3 \mu \mathrm{M}$ [38]. Beside, Apigenin, luteolin, and quercetin from the same plant showed potent activity against $3 \mathrm{CL}^{\text {pro }}$ in computational studies [38].

Baicalin: Baicalin is a glycosyloxy flavone found in Scutellaria baicalensis that shown inhibitory effects against atleast 10 different clinical isolates of SARS-CoV $[39,40]$. Intense inhibitory activity against SARS-CoV was detected in infected Vero cell lines $(\mathrm{EC50}=11 \mu \mathrm{g} / \mathrm{ml})[40]$. In a recent in-vitro analysis, baicalin was shown to inhibit highly conserved 3C-like protease $\left(3 \mathrm{CL}^{\text {pro }}\right)$ of SARS-CoV-2 [41]. Previously Baicalin was reported to inhibit cellular entry and replication of HIV-1 by conjugating with selected chemokines and inhibiting HIV-1 reverse transcriptase [42]. Besides, baicalin is an anti-inflammatory agent against $T$ lymphocyte activation and gene expression of pro-inflammatory cytokines, which supports its effectiveness against the pathogenesis of respiratory viruses like the RSV [39].

Cepharanthine: Cepharanthine (CEP), a bibenzyl isoquinoline alkaloid found in Stephania cepharantha Hayata, Stephania tetrandra, and some other allied species of Menispermaceae family $[43,44]$. It is used widely as conventional medicine in Japan in the treatment of many diseases like leukopenia, snake bites, xerostomia, and alopecia [43]. Beside, CEP has a potent anti-inflammatory, anti-proliferative, apoptotic, and immuno-modulatory effect [43]. The suppressive activity of CEP on the activation of inflammatory cytokine and chemokine reactions is the basis of its antiviral activity against the infection of HIV, Herpes virus, hepatitis B virus, and Coxsackie virus $[43,45]$. CEP inhibits HIV-1 cell entry by decreasing plasma membrane fluidity and reduces viral replication by inhibition of NFKB which acts as a strong regulator of HIV-1 gene expressions $[43,46,47]$. During the SARS-CoV outbreak in 2004, CEP showed inhibitory activity against the SARS-CoVinduced cytopathogenicity in Vero E6 cells infected by F69 strain, with an IC $\mathrm{IC}_{50}$ value ranging from of $6-9.5 \mu \mathrm{g} / \mathrm{ml}$ [48]. In a recent study, Cepharanthine alongside two other bis-benzyl isoquinoline alkaloids tetrandrine and fangchinoline were reported to reduce virus-induced cell death of human embryonal lung fibroblast cells (MRC-5), with potent inhibitory effect on viral protein expression (especially, Spike protein and Nucleoprotein) resulted in hindered replication of human coronavirus (HCoV-OC43) [44]. The inhibitory concentration ( $\left.\mathrm{IC}_{50}\right)$ of Cepharanthine on HCoV-OC43 was reported to be 729.7 $\mathrm{nM}$ [44]. In a recent investigation to repurpose clinically used drugs to treat CoVID-19, CEP was found to inhibit both entry (ACE2 inhibitor) and replication of 2019-nCoV-related pangolin coronavirus GX_P2Vwith an $\mathrm{EC}_{50}$ value of $0.98 \mu \mathrm{mol} / \mathrm{L}$ [49].

Emodin: Emodin ((1,3,8-trihydroxy-6-methylanthraquinone)) is a bioactive anthraquinone commonly found in the genus Rheum and Polygonum (particularly from Rheum rhabarbarum, Rheum officinale, and Polygonum multiflorum) $[50,51]$. This plant metabolite is a tyrosine kinase inhibitor, an antineoplastic agent, an anti-inflammatory, and a laxative agent [51]. Emodin isolated from $R$. officinale and $P$. multi- florum was found to interfere with the binding of S-protein to angiotensin-converting enzyme 2 (ACE2) receptor and reduced infectivity to Vero E6 cells by SARS-CoV with an IC value of $200 \mu \mathrm{M}$ [52]. An Emodin-derivative named as aloe-emodin (1,8-dihydroxy-3-hydroxyl-methylanthraquinone) reportedly inhibited the replication of several viruses including Novel Influenza A (H7N9) virus, Varicella zoster virus, Herpes simplex types 1 and 2 viruses, Pseudorabies virus, Human Cytomegalovirus, and/or Japanese encephalitis virus [53].

Ginsenoside-Rb1: Ginsenoside-Rb1 is pharmacologically active steroid glycosides or triterpene saponins of Panax ginseng and Panax japonicus used as an anti-inflammatory drug and radical scavenger [54]. Ginsenoside-Rb1 showed promising antiviral activity against SARS-coronaviruses at $100 \mu \mathrm{M}$, however, its mechanism of action is uninvestigated [34,55]. Ginsenoside-Rb1 and its structural analogues have been reported to inhibit host cell entry of influenza A virus [56] reduced cytopathogenicity of coxsackievirus B3, enterovirus 71, human rhinovirus 3 [57] and hepatitis A virus [58].

Glycyrrhizinor Glycyrrhizic acid: Glycyrrhizin or Glycyrrhizic acid, extracted from the root of Glycyrrhiza glabra and Glycyrrhiza radix was proved to be a potent antiviral agent against hepatitis $C$ virus which cause chronic liver diseases and where contemporary drugs are less effective $[59,60]$. Additionally, glycyrrhizin is well-known for its anti-inflammatory, antioxidative, anti-allergenic, and antimicrobial properties [61]. Glycyrrhizic acid and its derivatives exhibited a strong inhibitory effecton the in-vitro replication of SARS-coronavirus (SARS-CoV). A glycyrrhizin derivative with an added $\mathrm{N}$-acetylglucosamine residues in its carbohydrate part was found to be 10 -fold more effective than glycyrrhizin [60]. The $\mathrm{N}$-acetylglucosamine residue binds to the carbohydrates of the viral spike proteins (s-proteins) resulting in blocking of s-protein [60]. In addition to viral adsorption and penetration, glycyrrhizin exhibited an inhibitory effect on SARS-CoV replication and reducing viral cytopathogenicity with a selectivity index of 67 [62]. In a plaque reduction assay supported by neutralization tests, glycyrrhizin suppressed pathogenicity of several clinical isolates of SARS [40].

Leptodactylone: Leptodactylone is a hydroxycoumarin isolated from Boenninghausenia sessilicarpa [63]. Leptodactylone has shown an intense protective effect against viral cytopathogenicity in Vero E6 cells infected by SARS-CoV with concentration for $60 \%$ inhibition at $100 \mathrm{mg} / \mathrm{mL}$ [63]. Although, no significant information is available on its antiviral activity against other viral diseases as it remains a less explored antiviral phytocompound.

Lycorine: Lycorine, an alkaloid with broad antiviral activity found in several members of the Amaryllidaceae plant family [64]. It has potent antiviral activity against HIV-1, poliovirus, flaviviruses, human enterovirus 71 , and avian influenza virus H5N1 [64]. The broad-spectrum antiviral activity of lycorine is attributed to its ability to inhibit viral RNA replication and suppress viral protein synthesis [65]. Lycorine especially isolated from the plant Lycoris radiate exhibited potent inhibitory activity against SARS-CoV by reducing viral cytopathogenic effects with an inhibitory concentration $\left(\mathrm{EC}_{50}\right)$ as low as 15.7 
Citation: Laskar YB, Vandana UK, Roy S, et al. (2020) Antiviral Phytocompounds: A Methodical Review of Therapeutic Efficiency Against SARSLike Human Coronaviruses. J Plant Biotechnol Res 1(1):26-34

$\pm 1.2 \mathrm{nM}[66]$. Some recent computational studies suggested that lycorine might be a modulator of viral S-protein, however, the exact mechanism of action is still unclear.

Reserpine: Reserpine is an alkaloid, derived from the roots of Rauwolfia serpentine and Rauwolfia vomitoria, used as a peripheral antihypertensive and as a central depressant drug [67]. Reserpine was found to inhibit viral replication at an inhibitory concentration $\left(\mathrm{EC}_{50}\right)$ as low as $3.4 \mu \mathrm{M}$ when treated in SARS-CoV (H.K. strain) infected Vero E6 cells [34]. However; its adverse health effects limit its clinical use [67].

Saikosaponins: Saikosaponins are a group of oleanane byproducts, found in various plant families and well-known for their efficiency against viruses such as HIV, measles, influenza herpes simplex and varicella-zoster virus [68]. Saikosaponin B2 was reported to show selective growth inhibitory effects on the coronavirus strain, $\mathrm{HCoV}-229 \mathrm{E}$, with an $\mathrm{IC}_{50}$ value of $1.7 \mu \mathrm{mol} / \mathrm{L}$, cellular cytotoxicity value $\left(\mathrm{CC}_{50}\right)$ of $383.3 \mu \mathrm{mol} / \mathrm{L}$ and selectivity index (SI) of 221.9 [69]. The same study also reported the anti-CoV effect of saikosaponin A, C, and D with IC values of $8.6,19.9$, and $13.2 \mu \mathrm{mol} / \mathrm{L}$ respectively in 2 , 3-bis(2-methoxy-4-nitro-5-sulfophenyl)-2H- tetrazolium-5-carboxanilide (XTT) assay [69]. In general, these saikosaponins are predicted to inhibit the early stage of viral attachment, replication, and reducing aberrant pro-inflammatory cytokine production, however, the exact molecular mechanism is uninvestigated $[69,70]$.

Tanshinones: Tanshinones are a class of major bioactive ingredients of Salvia miltiorrhiza, known for their intense antioxidant, anti-inflammatory, and antineoplastic activity [71]. Tanshinones isolated from the dried roots of $S$. miltiorrhiza has shown selective inhibitory effects on $3 \mathrm{CL}^{\text {pro }}$ and $\mathrm{PL}^{\mathrm{pro}}$, and other viral cysteine proteases [72]. At least, seven of the tanshinones compounds namely tanshinone IIA, tanshinone IIB, methyl tanshinonate, cryptotanshinone, tanshinone I, dihydrotanshinone I, and rosmariquinone are reported to show inhibitory effects on viral cysteine proteases when expressed in E. coli BL21 (DE3) CodonPlus-RIL cells [72]. Except for rosmariquinone, all other compounds act as non-competitive enzyme isomerization inhibitors with concentration for $50 \%$ of the maximal effect ranging between 0.8 to $30.0 \mu \mathrm{M}$ [72]. Previously, extracts of $S$. miltiorrhiza and tanshinones were found to be active against other RNA viruses like enterovirus 71 [73] and porcine reproductive and respiratory syndrome virus [74].

Tetrandrine: Tetrandrine, a bisbenzyl isoquinoline alkaloid with a wide range of bioactivity, extracted from Stephania tetrandra other related species of Menispermaceae $[75,76]$. It has uses in Chinese traditional medicine as an analgesic and diuretic agent and is efficient against asthma, tuberculosis, malaria, cancer, and fever [75]. This alkaloid compound has been effectively used against the Ebola virus, HIV, and chloroquine-resistant strain of Plasmodium falciparum [75,77,78]. Plant-extracted Bis-benzyl isoquinoline alkaloids like cepharanthine and tetrandrine showed encouraging results against human coronavirus HCoV-OC43 in a recent study [44].

Theaflavin: Theaflavin and its derivatives (Theaflavins) are a class of naturally occurring flavonoids primarily found in black tea or Camellia sinensis [79]. These compounds are well-known for their antioxidant, anti-inflammatory, and other disease-curing abilities [79]. Previously, theaflavins and its derivatives were reported for their effectiveness against Influenza [80], HSV-1 [81], hepatitis C virus [82], calicivirus [83] and HIV-1 [84]. Besides preventing inflammatory cytokine expression, theaflavins are effective in thwarting viral attachment/entry and replication [82,84]. During the SARS outbreak in 2004, two theaflavin derivatives namely 3-isotheaflavin-3-gallate, theaflavin-3, 3'-digallate alongside tan-

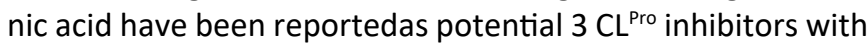
$\mathrm{IC}_{50}$ values 7, 9.5 and $3 \mu \mathrm{M}$ respectively [85]. Recently, a computerized docking study revealed that theaflavin could be a potential candidate for blocking RdRp protease of coronaviruses [86].

Xanthoangelol E: The leaves of Angelica keiskei is a rich source of naturally-occurring chalcones and coumarins like isobavachalcone, 4-hydroxyderricin, xanthoangelol \& its derivatives, psoralen, bergapten, xanthotoxin, and isopimpinellin $[87,88]$. Among these, the alkylated chalcones xanthoangelol $E$ exhibited a strong enzyme inhibitory effect against $3 \mathrm{CL}^{\text {pro }}$ and $\mathrm{PL}^{\text {pro }}$ of SARS-CoV when expressed in $E$. coli strain BL21 (DE3) in CodonPlus-RIL cells [88]. The mechanism was roughly estimated as competitive inhibition against $3 \mathrm{CL}^{\text {pro }}\left(\mathrm{IC}_{50}\right.$ $=11.4 \mu \mathrm{M})$ and noncompetitive enzyme inhibition in the case of $\mathrm{PL}^{\text {pro }}\left(\mathrm{IC}_{50}=1.2 \mu \mathrm{M}\right)$ [88].

Along with these compounds, four quinone-methide triterpenoid derivatives (iguesterin, tingenone, pristimererin, and celastrol) extracted from the bark of Tripteryguim regelii and five major phenolic compounds (sinigrin, indigo, aloe-emodin, hesperetin and $\beta$-sitosterol) from the root of Isatis indigotica were found to inhibit $3 \mathrm{CL}^{\text {pro }}$ of SARS-Coronavirus $[89,90]$. Procyanidin A2, procyanidin B1, and cinnam tannin B1fractionated from Cinnamomi cortex exhibited inhibitory effects against wild-type SARS-CoV infection demonstrated in a plaque reduction assay with $\mathrm{IC}_{50}$ values $37.35,15.69$ and $5.61 \mu \mathrm{M}$ respectively [91]. Quercetin-3- $\beta$-galactoside from Ginkgo biloba [92], Hirsutenone from Alnus japonica [93] inhibited SARS-CoV replication, while Myricetin isolated from Myrica rubra and Scutellarein isolated from Scutellaria baicalensis were reported as potent inhibitors of SARS-CoV helicase, nsp13 [94]. However, these compounds need a comprehensive investigation to be used as drug templates.

Among the raw plant tincture, the water extract of a traditional Chinese medicinal plant, Houttuynia cordata Thunb. (Saururaceae) exhibited a wide range of antiviral activity against SARS-CoV that includes inhibition of $3 \mathrm{CL}$ pro and RNA-dependent RNA polymerase (RdRp), increased $\mathrm{CD}^{+}: \mathrm{CD}^{+}$ratio, and elevated levels of cytokines (IL- 2 and IL-10) [95]. Also, the extracts of Rheum palmatum L., Isatis indigotica, Cibotium barometz, Gentiana scabra, Dioscorea batatas, Cassia tora, and Taxillus chinensis showed potent

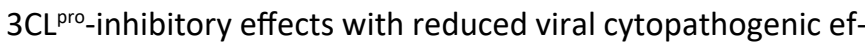
fect $[90,96,97]$. Further, the methanolic extracts of Tribulus terrestris and Paulownia tomentosa exhibited strong PL ${ }^{\text {pro-in- }}$ hibitory effects [98,99]. The alcoholic extracts of Euphorbia neriifolia, Toona sinensis, Cinnamomi cortex and Caryophylli flos reportedly linked with reduced viral cytopathogenicity 
Citation: Laskar YB, Vandana UK, Roy S, et al. (2020) Antiviral Phytocompounds: A Methodical Review of Therapeutic Efficiency Against SARSLike Human Coronaviruses. J Plant Biotechnol Res 1(1):26-34

and survival, with predicted inhibitory effects on viral replication $[91,100,101]$. These anti-SARS activities suggest the presence of potential therapeutic lead molecule in these plants that need a thorough investigation.

\section{Conclusion}

First discovered in the 1960s, these rapidly evolving viruses are emerging as a global public health threat as we are suffering the third major outbreak in the last 15 years. The ongoing Coronavirus Disease 2019 (CoVID-19) caused by SARS-CoV-2 virus, is one of the deadliest infectious disease outbreak since the Asian flu in the 1960s. Given our present understanding of the phylogeny and the pathogenesis of human coronaviruses, they share a typical genomic and clinical features which can be utilized to design a common therapy against them. One major setback of synthetic antivirals is virus developing resistance against them, which is relatively more robust in the case of RNA viruses with a rapid mutation capability. Besides, these diseases affect people from all economic domains hence not everyone can afford a foreseeable costly treatment. Thus exploring antiviral plants and their phytocompounds for treating coronaviral diseases could be a reliable and cost-effective alternative. Reportedly, several plants and their bioactive constituents exhibited strong antiviral activity against the pathogenesis of previous SARS-like diseases. However, as earlier SARS-like diseases disappeared rapidly, no significant progress has been made to link these findings to clinical and therapeutic assessment. Proper clinical investigation of phytocompounds that showed encouraging activity against the pathogenesis of RNA viruses especially against the previous SARS-like viruses may help us to design a cost-effective and efficient preventive remedy.

\section{Funding}

This research did not receive any specific grant from funding agencies in the public, commercial, or not-for-profit sectors.

\section{Conflict of Interest}

All the authors declare that they have no conflict of interest regarding this manuscript.

\section{Acknowledgements}

We would like to acknowledge DBT-Electronic Library Consortium (DeLCON) of Ministry of Science and Technology, Government of India for providing access to research articles.

\section{References}

1. Fung TS, Liu DX (2019) Human coronavirus: Host-pathogen interaction. Annu Rev Microbiol 73: 529-557.

2. Wölfel R, Corman VM, Guggemos W, et al. (2020) Virological assessment of hospitalized patients with COVID-2019. Nature 581: 465-469.

3. Forni D, Cagliani R, M Clerici, et al. (2017) Molecular evolution of human coronavirus genomes. Trends Microbiol 25: 35-48.

4. WHO (2015) Summary of probable SARS cases with onset of illness from 1 November 2002 to 31 July 2003.
5. WHO (2020) Middle East respiratory syndrome coronavirus (MERS-COV).

6. Lai CC, Shih TP, Ko WC, et al. (2020) Severe acute respiratory syndrome coronavirus 2 (SARS-CoV-2) and coronavirus disease-2019 (COVID-19): The epidemic and the challenges. Int J Antimicrob Agents 55: 105924.

7. WHO (2020) Coronavirus.

8. WHO (2020) Coronavirus Disease (COVID-19) Dashboard.

9. Alanagreh L, Alzoughool F, Atoum M (2020) The human coronavirus disease COVID-19: Its origin, characteristics, and insights into potential drugs and its mechanisms. Pathogens 9: 331.

10. Petrosillo N, Viceconte G, Ergonul O, et al. (2020) COVID-19, SARS and MERS: Are they closely related? Clin Microbiol Infect 26: 729-734.

11. Wu C, Liu Y, Yang Y, et al. (2020) Analysis of therapeutic targets for SARS-CoV-2 and discovery of potential drugs by computational methods. Acta Pharm Sin B 10: 766-788.

12. DeDiego ML, Nieto-Torres JL, Jimenez-Guardeño JM, et al. (2014) Coronavirus virulence genes with main focus on SARS-CoV envelope gene. Virus Res 194: 124-137.

13. He J, Hu L, Huang X, et al. (2020) Potential of coronavirus 3C-like protease inhibitors for the development of new anti-SARS-CoV-2 drugs: Insights from structures of protease and inhibitors. Int J Antimicrob Agents 56: 106055.

14. Barretto N, Jukneliene D, RatiaK, et al. (2005) The papain-like protease of severe acute respiratory syndrome coronavirus has deubiquitinating activity. J Virol 79: 15189-15198.

15. Báez-Santos YM, St John SE, Mesecar AD (2015) The SARS-coronavirus papain-like protease: Structure, function and inhibition by designed antiviral compounds. Antiviral Res 115: 21-38.

16. Venkataraman S, Prasad B, Selvarajan R (2018) RNA Dependent RNA Polymerases: Insights from structure, function and evolution. Viruses 10: 76.

17. Gao Y, Yan L, Huang Y, et al. (2020) Structure of the RNA-dependent RNA polymerase from COVID-19 virus. Science 368: 779-782.

18. Adedeji AO, Marchand B, te Velthuis AJW, et al. (2012) Mechanism of Nucleic Acid Unwinding by SARS-CoV Helicase. PLoS One 7: e36521.

19. Habtemariam S, Nabavi SF, Banach M, et al. (2020) Should we try SARS-CoV-2 helicase inhibitors for COVID-19 therapy? Arch Med Res 10-12.

20. Jacobs J, Zhou S, Dawson E, et al. (2010) Discovery of non-covalent inhibitors of the SARS main proteinase 3CLpro. National Center for Biotechnology Information (US).

21. Freitas BT, Durie IA, Murray J, et al. (2020) Characterization and noncovalent inhibition of the deubiquitinase and deisgylase activity of SARS-CoV-2 Papain-Like Protease. ACS Infect Dis 6: 2099-2109.

22. Cao B, Wang Y, Wen D, et al. (2020) A trial of lopinavir-ritonavir in adults hospitalized with severe Covid-19. N Engl J Med 382: 1787-1799.

23. Coomes EA, Haghbayan $H$ (2020) Favipiravir, an antiviral for COVID-19? J Antimicrob Chemother 75: 2013-2014.

24. Beigel JH, Tomashek KM, Dodd LE, et al. (2020) Remdesivir for the Treatment of Covid-19 - Preliminary Report. N Engl J Med 383:992-994. 
Citation: Laskar YB, Vandana UK, Roy S, et al. (2020) Antiviral Phytocompounds: A Methodical Review of Therapeutic Efficiency Against SARSLike Human Coronaviruses. J Plant Biotechnol Res 1(1):26-34

25. Chowdhury MS, Rathod J, Gernsheimer J (2020) A Rapid systematic review of clinical trials utilizing chloroquine and hydroxychloroquine as a treatment for COVID-19. Acad Emerg Med 27 493-504.

26. Gautret P, Lagier JC, Parola P, et al. (2020) Hydroxychloroquine and azithromycin as a treatment of COVID-19: results of an open-label non-randomized clinical trial. Int J Antimicrob Agents 56: 105949.

27. Şimşek YS, Ünal S (2020) Antiviral treatment of COVID-19. Turkish J Med Sci 50: 611-619.

28. Ang L, Lee HW, Choi JY, et al. (2020) Herbal medicine and pattern identification for treating COVID-19: A rapid review of guidelines. Integr Med Res 9: 100407.

29. Eddouks M, Chattopadhyay D, De Feo V, et al. (2012) Medicinal plants in the prevention and treatment of chronic diseases. Evid Based Complement Alternat Med 2012: 458274.

30. Mukhtar M, Arshad M, Ahmad M, et al. (2008) Antiviral potentials of medicinal plants. Virus Res 131: 111-120.

31. Jassim SAA, Naji MA (2003) Novel antiviral agents: A medicinal plant perspective. J Appl Microbiol 95: 412-427.

32. Ben-Shabat S, Yarmolinsky L, Porat D, et al. (2020) Antiviral effect of phytochemicals from medicinal plants: Applications and drug delivery strategies. Drug Deliv Transl Res 10: 354-367.

33. Guo Y, Cao Q, Hong Z, et al. (2020) The origin, transmission and clinical therapies on coronavirus disease 2019 (COVID-19) outbreak - an update on the status. Mil Med Res 7: 11.

34. Wu CY, Jan JT, Ma SH, et al. (2004) Small molecules targeting severe acute respiratory syndrome human coronavirus. Proc Natl Acad Sci 101: 10012-10017.

35. Sirtori CR (2001) Aescin: Pharmacology, pharmacokinetics and therapeutic profile. Pharmacol Res 44: 183-193.

36. Michelini FM, Alché LE, Bueno CA (2018) Virucidal, antiviral and immunomodulatory activities of $\beta$-escin and Aesculus hippocastanum extract. J Pharm Pharmacol 70: 1561-1571.

37. Yu S, Yan H, Zhang L, et al. (2017) A review on the phytochemistry, pharmacology, and pharmacokinetics of amentoflavone, a naturally-occurring biflavonoid. Molecules 22: 299.

38. Ryu YB, Jeong HJ, Kim JH, et al. (2010) Biflavonoids from Torreya nucifera displaying SARS-CoV 3 CLpro inhibition. Bioorg Med Chem 18: 7940-7947.

39. Shi H, Ren K, Lv B, et al. (2016) Baicalin from Scutellaria baicalensis blocks respiratory syncytial virus (RSV) infection and reduces inflammatory cell infiltration and lung injury in mice. Sci Rep 6: 35851.

40. Chen F, Chan K, Jiang Y, et al. (2004) In vitro susceptibility of 10 clinical isolates of SARS coronavirus to selected antiviral compounds. J Clin Virol 31: 69-75.

41. Su H, Yao S, Zhao W, et al. (2020) Discovery of baicalin and baicalein as novel, natural product inhibitors of SARS-CoV-2 $3 \mathrm{CL}$ protease in vitro. Bio Rxiv Prepr 20200413038687.

42. Li BQ, Fu T, Dongyan Y, et al. (2000) Flavonoid Baicalin Inhibits HIV-1 Infection at the Level of Viral Entry. Biochem Biophys Res Commun 276: 534-538.

43. Bailly C (2019) Cepharanthine: An update of its mode of action, pharmacological properties and medical applications. Phytomedicine 62: 152956.
44. Kim, Min, Jang, et al. (2019) Natural bis-benzylisoquinoline alkaloids-tetrandrine, fangchinoline, and cepharanthine, inhibit human coronavirus $\mathrm{OC} 43$ infection of MRC- 5 human lung cells. Biomolecules 9: 696 .

45. Zhou YB, Wang YF, Zhang Y, et al. (2012) In vitro activity of cepharanthine hydrochloride against clinical wild-type and lamivudine-resistant hepatitis B virus isolates. Eur J Pharmacol 683: 10-15.

46. Matsuda K, Hattori S, Komizu Y, et al. (2014) Cepharanthine inhibited HIV-1 cell-cell transmission and cell-free infection via modification of cell membrane fluidity. Bioorg Med Chem Lett 24: 2115-2117.

47. Okamoto M, Ono M, Baba M (1998) Potent Inhibition of HIV Type 1 Replication by an Antiinflammatory Alkaloid, Cepharanthine, in Chronically Infected Monocytic Cells. AIDS Res Hum Retroviruses 14: 1239-1245.

48. Zhang C, Wang Y, Liu X, et al. (2005) Antiviral activity of cepharanthine against severe acute respiratory syndrome coronavirus in vitro. Chin Med J (Engl) 118: 493-496.

49. Fan HH, Wang LQ, Liu WL, et al. (2020) Repurposing of clinically approved drugs for treatment of coronavirus disease 2019 in a 2019-novel coronavirus-related coronavirus model. Chin Med J (Engl) 133: 1051-1056.

50. Alves DS, Pérez-Fons L, Estepa A, et al. (2004) Membrane-related effects underlying the biological activity of the anthraquinones emodin and barbaloin. Biochem Pharmacol 68: 549-561.

51. X Dong, J Fu, X Yin, et al (2016) Emodin: A review of its pharmacology, toxicity and pharmacokinetics. Phyther Res 30: 12071218.

52. T Ho, S Wu, J Chen, et al. (2007) Emodin blocks the SARS corona virus spike protein and angiotensin-converting enzyme 2 interaction. Antiviral Res 74: 92-101.

53. S W Li, T C Yang, C C Lai, et al. (2014) Antiviral activity of aloe-emodin against influenza a virus via galectin-3 up-regulation. Eur J Pharmacol 738: 125-132.

54. P Mohanan, S Subramaniyam, R Mathiyalagan, et al. (2018) Molecular signaling of ginsenosides $\mathrm{Rb} 1, \mathrm{Rg} 1$, and $\mathrm{Rg} 3$ and their mode of actions. J Ginseng Res 42: 123-132.

55. D L Barnard, Y Kumaki (2011) Recent developments in anti-severe acute respiratory syndrome corona virus chemotherapy. Future Virol 6: 615-631.

56. W Dong, A Farooqui, A J Leon, et al. (2017) Inhibition of influenza a virus infection by ginsenosides. PLoS One 12: e0171936.

57. J H Song, H J Choi, H H Song, et al. (2014) Antiviral activity of ginsenosides against coxsackievirus $\mathrm{B} 3$, enter virus 71 , and human rhinovirus 3. J Ginseng Res 38: 173-179.

58. M H Lee, B H Lee, S Lee, et al. (2013) Reduction of hepatitis a virus on frhk- 4 cells treated with Korean red ginseng extract and ginsenosides. J Food Sci 78: M1412-M1415.

59. U A Ashfaq, M S Masoud, Z Nawaz, et al. (2011) Glycyrrhizin as antiviral agent against hepatitis $C$ virus. J Transl Med 9: 112.

60. G Hoever, L Baltina, M Michaelis, et al. (2005) Antiviral activity of glycyrrhizic acid derivatives against SARS-corona virus. J Med Chem 48: 1256-1259.

61. YJ Kwon, DH Son, TH Chung, et al. (2020) A review of the pharmacological efficacy and safety of licorice root from corroborative clinical trial findings. J Med Food 23: 12-20. 
Citation: Laskar YB, Vandana UK, Roy S, et al. (2020) Antiviral Phytocompounds: A Methodical Review of Therapeutic Efficiency Against SARSLike Human Coronaviruses. J Plant Biotechnol Res 1(1):26-34

62. J Cinatl, B Morgenstern, G Bauer, et al. (2003) Glycyrrhizin, an active component of liquorice roots, and replication of SARS-associated coronavirus. Lancet 361: 2045-2046.

63. QY Yang, XY Tian, WS Fang (2007) Bioactive coumarins from Boenninghausenia sessilicarpa, J Asian Nat Prod Res 9: 59-65.

64. Z Cao, P Yang, Q Zhou (2013) Multiple biological functions and pharmacological effects of lycorine. Sci China Chem 56: 13821391.

65. J He, WB Qi, L Wang, et al. (2013) Amaryllidaceae alkaloids inhibit nuclear-to-cytoplasmic export of ribonucleoprotein (RNP) complex of highly pathogenic avian influenza virus H5N1. Influenza Other Respi Viruses 7: 922-931.

66. S Li, C Chen, H Zhang, et al. (2005) Identification of natural compounds with antiviral activities against SARS-associated coronavirus. Antiviral Res 67: 18-23.

67. K Traylor, H Gurgle, K Turner, et al. (2017) Antihypertensive Drugs, in: Side eff drugs Annu, 1st ed, Elsevier BV, pp 183-187.

68. B Yuan, R Yang, Y Ma, et al. (2017) A systematic review of the active saikosaponins and extracts isolated from Radix Bupleuri and their applications. Pharm Biol 55: 620-635.

69. PW Cheng, LT Ng, LC Chiang, et al. (2006) Antiviral effects of saikpsaponins on human coronavirus 229e in vitro. Clin Exp Pharmacol Physiol 33: 612-616.

70. J Chen, M Duan, Y Zhao, et al. (2015) Saikosaponin a inhibits influenza a virus replication and lung immunopathology. Oncotarget 6: 42541-42556.

71. Z Jiang, W Gao, L Huang (2019) Tanshinones, Critical Pharmacological Components in Salvia miltiorrhiza. Front Pharmacol 10: 202.

72. J-Y Park, JH Kim, YM Kim, et al. (2012) Tanshinones as selective and slow-binding inhibitors for SARS-CoV cysteine proteases. Bioorg Med Chem 20: 5928-5935.

73. BW Wu, TL Pan, YL Leu, et al. (2007) Antiviral Effects of Salvia miltiorrhiza (Danshen) against enterovirus 71. Am J Chin Med 35: 153-168.

74. N Sun, P Sun, M Yao, et al. (2019) Autophagy involved in antiviral activity of sodium tanshinone IIA sulfonate against porcine reproductive and respiratory syndrome virus infection in vitro. Antivir Ther 24: 27-33.

75. N Bhagya, KR Chandrashekar (2016) Tetrandrine - A molecule of wide bioactivity. Phytochemistry 125: 5-13.

76. G Wang, JR Lemos, C ladecola (2004) Herbal alkaloid tetrandrine: from an ion channel blocker to inhibitor of tumor proliferation. Trends Pharmacol Sci 25: 120-123.

77. Y Sakurai, AA Kolokoltsov, C Chen, et al. (2015) Two-pore channels control Ebola virus host cell entry and are drug targets for disease treatment, Science 347: 995-998.

78. Z Ye, K Van Dyke, RN Rossan (2013) Effective treatment with a tetrandrine/chloroquine combination for chloroquine-resistant falciparum malaria in Aotus monkeys. Malar J 12: 117

79. H Babich, RT Gottesman, EJ Liebling, et al. (2008) Theaflavin-3-Gallate and Theaflavin-3'-Gallate, Polyphenols in black tea with prooxidant properties. Basic Clin Pharmacol Toxicol 103: 66-74

80. M Zu, F Yang, W Zhou, et al. (2012) In vitro anti-influenza virus and anti-inflammatory activities of theaflavin derivatives. Antiviral Res 94: 217-224.

81. A de Oliveira, D Prince, C-Y Lo, et al. (2015) Antiviral activity of theaflavin digallate against herpes simplex virus type 1 . Antiviral Res 118: 56-67.

82. P Chowdhury, ME Sahuc, Y Rouillé, et al. (2018) Theaflavins, polyphenols of black tea, inhibit entry of hepatitis $C$ virus in cell culture, PLoS One 13 e0198226.

83. M Ohba, T Oka, AndoT, et al. (2017) Antiviral effect of theaflavins against caliciviruses. J Antibiot (Tokyo) 70: 443-447.

84. S Liu, H Lu, Q Zhao, et al. (2005) Theaflavin derivatives in black tea and catechin derivatives in green tea inhibit HIV-1 entry by targeting gp41, Biochim Biophys Acta - Gen Subj 1723: 270-281.

85. CN Chen, CPC Lin, KK Huang, et al. (2005) Inhibition of SARS-CoV 3C-like Protease Activity by Theaflavin-3,3'-digallate (TF3). Evi Based Complement Altern Med 2: 209-215.

86. J Lung, Y Lin, Y Yang, et al. (2020) The potential chemical structure of anti-SARS-CoV-2 RNA-dependent RNA polymerase, J Med Virol 92: 693-697.

87. H Ohnogi, Y Kudo, K Tahara, et al. (2012) Six new chalcones from angelica keiskei inducing adiponectin production in 3T3-L1 adipocytes. Biosci Biotechnol Biochem 76: 961-966.

88. JY Park, JA Ko, DW Kim, et al. (2016) Chalcones isolated from Angelica keiskei inhibit cysteine proteases of SARS-CoV. J Enzyme Inhib Med Chem 31: 23-30.

89. YB Ryu, SJ Park, YM Kim, et al. (2010) SARS-CoV 3CL pro inhibitory effects of quinone-methide triterpenes from Tripterygium regelii. Bioorg Med Chem Lett 20: 1873-1876.

90. CW Lin, FJ Tsai, CH Tsai, et al. (2005) Anti-SARS coronavirus $3 \mathrm{C}$-like protease effects of Isatis indigotica root and plant-derived phenolic compounds. Antiviral Res 68: 36-42.

91. M Zhuang, H Jiang, Y Suzuki, et al. (2009) Procyanidins and butanol extract of Cinnamomi Cortex inhibit SARS-CoV infection. Antiviral Res 82: 73-81.

92. L Chen, J Li, C Luo, et al. (2006) Binding interaction of quercetin-3- $\beta$-galactoside and its synthetic derivatives with SARS-CoV 3CLpro: Structure-activity relationship studies reveal salient pharmacophore features. Bioorg Med Chem 14: 8295-8306.

93. JY Park, HJ Jeong, JH Kim, et al. (2012) Diarylheptanoids from alnus japonica inhibit papain-like protease of severe acute respiratory syndrome coronavirus. Biol Pharm Bull 35: 2036-2042.

94. MS Yu, J Lee, JM Lee, et al. (2012) Identification of myricetin and scutellarein as novel chemical inhibitors of the SARS coronavirus helicase, nsP13. Bioorg Med Chem Lett 22: 4049-4054.

95. KM Lau, KM Lee, CM Koon, et al. (2008) Immunomodulatory and anti-SARS activities of Houttuynia cordata. J Ethnopharmacol 118: 79-85.

96. W Luo, X Su, S Gong, et al. (2009) Anti-SARS coronavirus 3C-like protease effects of Rheum palmatum $L$ extracts. Biosci Trends 3: 124-6.

97. CC Wen, LF Shyur, JT Jan, et al. (2011) Traditional Chinese medicine herbal extracts of Cibotium barometz, Gentiana scabra, Dioscorea batatas, Cassia tora, and Taxillus chinensis inhibit SARSCoV replication. J Tradit Complement Med 1: 41-50.

98. YH Song, DW Kim, MJ Curtis-Long, et al. (2014) Papain-Like Protease (PLpro) inhibitory effects of cinnamic amides from tribulus terrestris fruits. Biol Pharm Bull 37: 1021-1028.

99. JK Cho, MJ Curtis-Long, KH Lee, et al. (2013) Geranylated flavonoids displaying SARS-CoV papain-like protease inhibition from the fruits of Paulownia tomentosa. Bioorg Med Chem 21: 30513057.

100. FR Chang, CT Yen, M EIShazly, et al. (2012) Anti-Human Coronavirus (anti-HCoV) triterpenoids from the leaves of euphorbia neriifolia. Nat Prod Commun 7: 1415-1417.

101. CJ Chen, M Michaelis, HK Hsu, et al. (2008) Toona sinensis Roem tender leaf extract inhibits SARS coronavirus replication. J Ethnopharmacol 120: 108-111. 